\title{
Symptomatic esophageal stricture and buried metaplasia after radiofrequency ablation of Barrett's esophagus
}

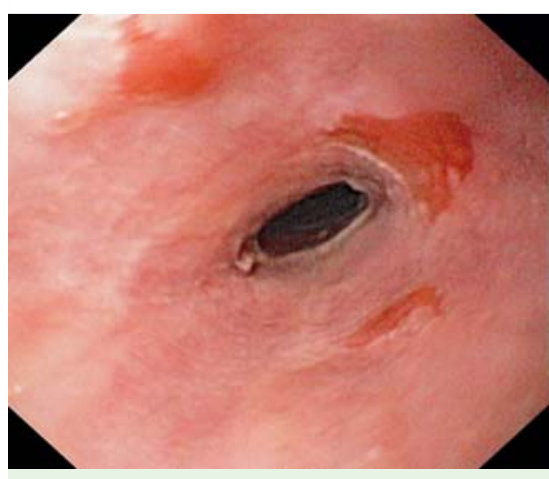

Fig. 1 Endoscopic view of a tight esophageal stricture post radiofrequency ablation (RFA); the stricture is located in the mid portion of the original Barrett's esophagus segment (the stricture could be traversed after balloon dilation only). Note the persisting three salmoncolored islands (intestinal metaplasia at pathological examination) in the re-epithelialized squamous mucosa proximal to the stricture.

A 64-year-old woman with high-grade dysplasia (HGD) arising in Barrett's esophagus was referred for treatment. Endoscopy with narrow band imaging confirmed the presence of Barrett's esophagus (Prague C13M14) and no irregularity was detected at this level. Radiofrequency ablation (RFA) was the only treatment given, using the HALO system (BÂRRX Medical Inc., Sunnyvale, California, USA) in a standard manner, by an endoscopist highly experienced in this technique [1,2]. After measuring the inner esophageal diameter, two consecutive circumferential ablations $\left(12 \mathrm{~J} / \mathrm{cm}^{2}, 40 \mathrm{~W} / \mathrm{cm}^{2}\right)$ were carried out using a 31-mm in-diameter balloon, with removal of tissue debris between ablations using a cap-fitted endoscope. The procedure was uneventful and esomeprazole (40 mg twice daily) was prescribed. Ten weeks later the patient (still taking esomeprazole) presented with dysphagia. An upper endoscopy disclosed a stricture and neosquamous mucosa with salmon-col-

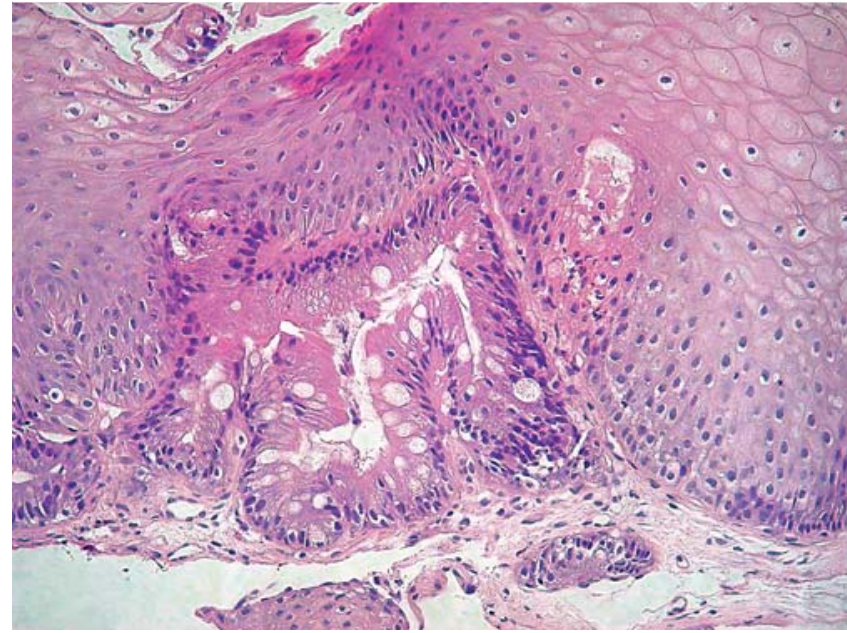

Fig. 2 Buried Barrett's metaplasia at microscopic examination of routine biopsy sample 10 weeks post radiofrequency ablation (RFA) (hematoxylin and eosin stain, magnification $\times 100)$.

ored islands ( $\bullet$ Fig. 1). Four-quadrant biopsies (every $2 \mathrm{~cm}$ ) from the original Barrett's esophagus segment disclosed no residual dysplasia, but buried glands were detected in one specimen sampled above the stricture ( $\bullet$ Fig. 2 ). The stricture was dilated twice with a balloon (up to a diameter of $18 \mathrm{~mm}$ ), and 12 months after the RFA, the patient is doing well with neither residual dysphagia nor dysplasia. However, the buried glands are more widespread (detected in biopsies at four out of seven sampled levels). No more RFA has been attempted and the patient remains under close endoscopic surveillance.

RFA has recently been proposed as a treatment for not only Barrett's HGD and intramucosal cancer [2] but also nondysplastic Barrett's esophagus [3]. It has been suggested that RFA does not have the drawbacks associated with other ablation techniques, in particular esophageal stricture and buried glands [2]. Our patient developed symptomatic esophageal stricture after RFA alone; this could have been because of the unusual length of Barrett's esophagus ablation [4]. Detection of buried glands has been reported in a single case after RFA [3]. This is of concern because the true extent of Barrett's esophagus is obscured, making endoscopic screening less reliable; moreover, adenocarcinoma has been reported to arise from buried glands after other ablative techniques [5]. In our case, sampling close to a neosquamo-columnar junction seems unlikely.

Endoscopy_UCTN_Code_CCL_1AB_2AC_3AC

F.Janssens ${ }^{1}$, A. L. Rougemont ${ }^{2}$, J. Deviere ${ }^{3}$, P. Fockens ${ }^{4}$,

J. M. Dumonceau ${ }^{1}$

Service of Gastroenterology and Hepatology, Geneva University Hospitals, Geneva, Switzerland

2 Service of Anatomopathology, Geneva University Hospitals, Geneva, Switzerland

3 Departments of Gastroenterology and Hepato-Pancreatology, Erasme University Hospital, Université Libre de Bruxelles, Brussels, Belgium

4 Department of Gastroenterology and Hepatology, Academic Medical Center, University of Amsterdam, Amsterdam, The Netherlands 


\section{References}

1 Gondrie JJ, Pouw RE, Sondermeijer CM et al. Effective treatment of early Barrett's neoplasia with stepwise circumferential and focal ablation using the HALO system. Endoscopy 2008; 40: 370-379

2 Pouw RE, Sharma VK, Bergman JJ et al. Radiofrequency ablation for total Barrett's eradication: a description of the endoscopic technique, its clinical results and future prospects. Endoscopy 2008; 40: 1033-1040
3 Hernandez JC, Reicher S, Chung D et al. Pilot series of radiofrequency ablation of Barrett's esophagus with or without neoplasia. Endoscopy 2008; 40: 388-392

4 Overholt BF. Photodynamic therapy strictures: who is at risk? Gastrointest Endosc 2007; 65: 67-69

5 Van Laethem JL, Peny MO, Salmon I et al. Intramucosal adenocarcinoma arising under squamous re-epithelialisation of Barrett's oesophagus. Gut 2000; 46: 574-577
Bibliography

DOI $10.1055 / \mathrm{s}-0029-1214983$

Endoscopy 2009; 41: E214-E215

(c) Georg Thieme Verlag KG Stuttgart · New York . ISSN 0013-726X

\section{Corresponding author}

\section{J. M. Dumonceau, MD, PhD}

Division of Gastroenterology and Hepatology Geneva University Hospitals

Micheli-du-Crest street

241205 Geneva

Switzerland

Fax: +41-22-3729366

jmdumonceau@hotmail.com 